\title{
Pensamientos de un violador en serie
}

\begin{abstract}
J avier Urrá ${ }^{*}$
Fiscalía del Tribunal Superior de J usticia y de los Juzgados de Menores de Madrid Asociación Iberoamericana de Psicología J urídica Universidad Complutense de Madrid
\end{abstract}

Recibido: Septiembre 7 de 2005 Revisado: Octubre 26 de 2005 Aceptado: Noviembre 2 de 2005

\section{Resumen}

El presente artículo corresponde a un estudio de caso, en el que el autor describe material obtenido de trabajar directamente con V.S.R., con el fin de ilustrar los pensamientos de un violador en serie $y$, a la vez, esclarecer algunos elementos teóricos del psicópata. El documento describe a V.S.R. como un condenado a pena de prisión de 20 años por tres violaciones consumadas, al cumplir 23 años y estando en un centro de reforma, puede reingresar a prisión o bien quedar en la calle con una medida de libertad vigilada. Se solicita informe del Psicólogo Forense adscrito a la Fiscalía para su evaluación y orientación de la medida. A través de las entrevistas y análisis del expediente llegaremos a conocer los verdaderos pensamientos y patología de un agresor sexual reiterativo.

Palabras clave: agresor sexual, psicópata, entrevista, forma de pensar 


\section{Abstract}

The present article corresponds to a case study, in which the author describes material obtained by working directly with V.S.R., with the purpose of simultaneously illustrate the thoughts of a serial rapist and clarify some theoretical elements of psychopath. The document describes to V.S.R. like condemned man to 20 prison years by three accomplished violations, when he was 23 years and being in Reformation Center, he can return to prison or to be in the street with watched over freedom measure. The forensic psychologist's report is requested to the District Attorney's Office for its evaluation and orientation of the measure. Through the interviews and file analysis, we will be able to know the iterative sexual aggressor's true thoughts and pathology.

Key words: sexual aggressor, psychopath, interview, thinking way.

Nota: Las fechas, lugares y nombres que aparecen no coinciden con las auténticas, por lo demás, el caso es absolutamente real.

\section{Decreto del Fiscal Coordinador de la Sección de Menores del Tribunal Superior de J usticia de Madrid}

Examinado el expediente de ejecución núm. XX/ 2003 de esta Fiscalía se observa que V.S.R. está a punto de cumplir los 23 años, edad que determina la revisión de su situación personal. Con el fin de disponer de la información adecuada solicitamos que por D. J avier Urrá se proceda a realizar aqueIlas actuaciones que sean precisas para llegar al más acertado diagnóstico.

Lo manda y firma S.I.

Diez de junio de dos mil cuatro.

\section{Informe psicológico del interno V.S.R.}

El joven de 22 años (cumple 23 en julio), V.S.R., y por propia voluntad, indicó a los miembros de dirección, sabedor de mis visitas de inspección de la Fiscalía al Centro de Reforma El Pinar, su interés por entrevistarse con el psicólogo firmante. Lo que se llevó a efecto el 6 de junio.
El menor fue detenido cuando contaba con 17 años, juzgado y condenado a pena de prisión de 20 años por tres violaciones consumadas; habiéndose procedido a reconocimiento, lo fue por tres víctimas.

Ejercido Derecho Transitorio, por entrada en vigor de la Ley Orgánica de Responsabilidad Penal del Menor 5/ 2000, obra Auto 3 de mayo de 2003 (recuérdese que las fechas son ficticias), por el que se sustituye la pena de prisión de 20 años por la medida de 3 años de internamiento en centro cerrado de reforma de menores El Pinar, junto con la medida terapéutica consistente en la inclusión en un programa de prevención de reincidencias y readaptación al medio social, complementadas con una medida de 5 años de libertad vigilada.

Su pena ha sido de cuatro años, en las prisiones de Alcalá Meco-jóvenes; Aranjuez y Navalcarnero, a lo que ha de sumarse que lleva al go más de un año en el Centro de Reforma El Pinar. En total cinco años de privación de libertad.

El 7 de julio cumple los 23 años, por lo que se produce una disyuntiva compleja, difícil y de riesgo, 0 bien reingresa en prisión (lo que parece ilógico y poco pertinente para quien ha estado en un centro 
de reforma de menores) o bien queda en la calle con una medida de libertad vigilada (que en nada impide su movilidad y consecuente riesgo conductual).

La encrucijada es tomar el camino de un riesgo hasta dónde es posible, evaluado en aras de una resocialización individualmente valorada y aj ustada, o por el contrario y en bien de la prevención general de hipotéticas futuras víctimas potenciales y del equilibrado y coherente reproche social, mantener al joven privado de libertad (Urrá, 2002).

Dado que el 4 de junio se le concedió el paso a centro semi-abierto y que el 6 del mismo mes se encontraba junto a los profesionales de la Asociación J unco en búsqueda de empleo, el firmante estimó citarle en la Plaza Mayor de Madrid y paseando por sus soportales se realizó la entrevista.

Su presencia física es correctísima, su tono muy agradable, su mímica y comunicación gestual acorde con sus palabras. Habla con fluidez, con un ritmo y cadencia normalizados (sin silencios por schock negativos, ni verborreas). ¿Cuál es la impresión de este psicólogo forense tras el encuentro?: de falta de naturalidad por parte de V.S.R. Todo ha sido idílico, medido.

Cabe una perturbadora duda, iha cambiado tanto que es una persona distinta de quien violó con reiteración o estamos ante un psicópata que ha aprendido a mostrarse educado, correcto y, por tanto, más psicopático?

Se muestra modélico "soy meticuloso", "tengo que ser perfeccionista", estamos ante un pensamiento rígido muy, muy trabajado por él durante estos cinco años.

¿Cómo interpretar la expresión "la experiencia de la cárcel te hace fuerte moralmente"? (¿Ha madurado como persona y miembro social? O por el contrario ¿se ha hecho más astuto, con capacidad de planificar, de eludir riesgos...?).

Se cree muy convincente -lo es-. Sin embargo hay algunas incoherencias preocupantes, por ejemplo, valora a sus padres como un entorno positivo y a su familia como de apoyo, sin embargo abandonó los estudios a los 14 años, ayudó como carnicero de los 14 a los 17 años (no se puede legalmente trabajar hasta los 16), pasaba las noches enteras en la calle "en malas compañías de más edad", ingería anfetaminas y ácido lisérgico (L.S.D. ), salía a la calle siempre con un estilete (algo que realizaba bajo su consciencia y voluntad, no bajo los efectos de ninguna droga), fue reiterativo en los gravísimos hechos. Además, su hermano mayor heroinómano está en la cárcel por múltiples conductas delictivas.

No, no todo encaj a, afirma "No hay riesgo de reincidencia. Estoy seguro, porque he cambiado, ya no estoy en el mundo de las drogas" (cree haber cambiado, o dice haber cambiado), pero ¿cómo está tan seguro de que no reincidirá en su drogodependencia de fin de semana o en sus abusos sexuales? La falta de una mínima duda razonable resulta preocupante.

¿Está arrepentido, asume responsabilidades? En el momento de sus violencias sexuales con arma: No. "Después del hecho no hay sensación, se continúa la fiesta de drogas..." ¿ ¿Y después?, explica que sí "Me he machacado psicológicamente pensando en las víctimas. Cuando piensas en lo que sufren, empatizas. Lo he pensado mucho. Seguro que les han quedado secuelas, es irreparable" (la impresión subjetiva del firmante es que lo dice como se recita una lección aprendida ¿no lo siente o lo ha repetido mucho?). En todo caso y a preguntas explícitas "Io pensaba antes, ahora no porque soy otra persona".

Cuando se le formula si ha pensado en pedir perdón a las víctimas es la primera vez que tarda en contestar, se toma su tiempo y responde "Ni el perdón serviría. Creo que rememorarlo sería lesivo para ellas. Me gustaría que supieran que estoy arrepentido". No quiere enfrentarse a ellas, tiene miedo a enfrentarse a la realidad, las víctimas pueden producirle horror o incontinencia, quizás piense que ante su presencia puede perder el control). Muchas de sus respuestas son fruto de un aprendizaj e conseguido en los tres años en que ha asistido a tratamiento psicológico ( 2 en Alcalá 
Meco-jóvenes +1 en El Pinar), tanto individual como grupal, eso no presupone falsedad. Habla magníficamente de los profesionales con los que ha entrado en contacto. Ha obtenido el graduado escolar y está convencido de que obtendrá pronto un trabajo (reparación de ascensores o ayudante en un supermercado).

Respecto a su futuro inmediato expone "me veo trabajando, vivir en casa con mis padres, luego independizarme y vivir con una chica, alcanzar la estabilidad y viajar (en moto por España), disfrutar de mi libertad". Su conducta futura es desde nuestro criterio impredecible, más por la tipología de los hechos cometidos, pues pareciera que nos encontramos ante alguien con un trastorno de la personalidad de base psicopática. Añádase que no hay un tratamiento psicoterapeútico efectivo (reconocido por la comunidad científica) para los abusadores sexuales en serie. $Y$ este es el caso.

V.S.R. no asume responsabilidades, porque se las deriva a las drogas consumidas. Además a la pregunta de por qué asume que lo ha hecho en tres ocasiones si como dice no recuerda nada, contesta "porque fui reconocido" (no puede negar la evidencia, pero es -vuelve a ser-externa).

No debiera conseguir desviar la atención de la etiología de su problemática con un "activador" como las drogas. Porque lo que hay que concluir es si estamos ante un individuo con un gravísimo trastorno psicopático de la personalidad que es además un sádico sexual (que pasó de la fantasía al acto), porque entonces y como expone el Manual diagnóstico y estadístico de los trastornos mentaIes D.S.M. - IV, de la American Psychiatric Association, en el diagnóstico F65. 5 Sadismo Sexual [302.84] es crónico (Urrá, 2003).

En todo caso y de tomarse el más que manifiesto riesgo de que quede en libertad vigilada, la misma debe llenarse de un contenido de supervisión estrictísimo, que garantice que sigue milimétricamente las directrices del terapeuta que necesariamente se le ha de asignar.
$Y$ dicho lo anterior volvamos a interrogarnos en voz alta o reflexionar.

¿Cuál fue la impresión del firmante tras la primera entrevista? De un intento de seducción por parte de V.S.R., de un exceso de seguridad personal, de una naturalidad impropia para quien no te conoce, para quien pasea con alguien que representa la autoridad (viene de la Fiscalía), que es un personaj e reconocido (ha sido durante cinco años el Defensor del Menor), que es saludado en la Plaza Mayor por los miembros de la Policía Nacional de proximidad...

¿Tiene una imagen hipertrofiada de sí mismo, está afecto de grandiosidad?

Y sin embargo subj etivamente se aprecia distanciamiento afectivo, habla, gesticula, pero es como quien baila sin música (pareciera que hay mucho de aprendido). Hay que contestar lo más simple, lo más difícil ¿por qué lo hizo?, es la única forma de aproximarse al riesgo de reincidencia. ¿Es un perverso? ¿Tiene una mala imagen de la mujer (de la madre -como valoraba Melanie Klein-)? Para dar respuestas (o intentarlo) a tantas preguntas hay que consultar los informes anteriores y hablar con los psicólogos que lo han explorado y tratado. Así lo comunico al Fiscal coordinador de la Sección de Menores y a la Fiscal responsable de ej ecución, me dan vía libre para seguir investigando e informándoles.

El 9 de abril me desplacé al Centro de El Pinar, para mantener una sesión clínica con el psicólogo del Centro. Al acabar mi impresión, expuso que a él también le asaltan muchísimas dudas, que hay indicios de que V.S.R. no ha modificado su posicionamiento, que ciertamente asume lo que ha hecho pero que entiende que lo ha pagado con su libertad, pero que no ha interiorizado lo que significa.

Dado que en esta sesión clínica hay confluencia de criterios pre-diagnósticos de índole subjetiva entendida como observacional y de inferencias lógicas, le propongo explorar conjuntamente a V.S.R. el 13 de junio. 
Concretamos que en primer lugar le administraremos el test de personalidad 16. P.F., para ulteriormente y en la entrevista clínica hacer hincapié en: Anamnesis e historia personal. Sexualidad vivida y fantaseada. Apreciación de los hechos delincuenciales. Verbalización de su adicción a las drogas. Interpretación del impacto que cree causó en las víctimas. Características físicas de las agredidas y razones para su elección.

Buscamos captar -si es factible-, su realidad emocional. Prevemos golpear su capacidad para aceptar la frustración, mostrarle nuestras dudas, nuestra desconfianza. Penetrar en su yo profundo, en ése que recubre, que oculta o desconoce. Para esta exploración psicológica a calibrar en el centro El Pinar se precisa leer con detalle todo el expediente de V.S.R. y dado que este caso se está abordando desde casi el final al principio, seguiremos ese criterio. A continuación se expone un extracto con los momentos y datos más significativos del mismo.

\section{Informe educativo-social. Del expediente de Derecho Transitorio DD/2002, elaborado por el Equipo Técnico № 5 de la Fiscalía de Menores, 8 de abril de 2003}

\author{
V.S.R.: 21 años y 10 meses. \\ - Intervenciones realizadas: entrevista con el equipo \\ de tratamiento del Centro Penitenciario Madrid IV \\ (Navalcarnero), con fecha 7/ IV/ 02. Entrevista con \\ el suj eto con fecha 7/ IV/ 02.
}

- Interno en: Centro Penitenciario Madrid IV (Navalcarnero, desde el 1/ VII/02). Procedía del Centro Penitenciario Madrid VI (Aranjuez) donde estaba bajo medidas especiales de seguridad, desde el inicio de la pena, por dificultades con otros internos.

- Condena cumplida: 4 años y 10 meses.

- Condena pendiente: 15 años y 2 meses.
La valoración de los firmantes no es positiva, ni optimista: “...debe considerarse que por los factores descritos como relevantes para su comportamiento delictivo muestra una conducta voluntaria, consciente y reiterada". La acorde orientación de medida deja en suspenso el "reingreso en prisión al alcanzar los 23 años o la sustitución en su momento de la pena restante por una medida de Libertad Vigilada".

Relativo al área familiar, se constata que "el padre padece enfermedad irreversible asociada al consumo de sustancias tóxicas...". "Antecedentes toxicofílicos de su hermano". No parece compatible la realidad con lo que me contó en la Plaza Mayor de Madrid en donde valoró a sus padres como un entorno positivo y a su familia como de apoyo (¿Piensa que no indagaré?). Relativo al mutuo acuerdo en la ruptura de la relación de noviazgo sólo tenemos una versión, la de V.S.R., y ciertamente su credibilidad siempre debe ser cuestionada.

La explicación reiterativa por la que establece una relación causa-efecto entre el consumo de droga y los hechos por los que ha sido condenado nos obliga a preguntarnos ino percibe que esta explicación no es creída por nadie, que no puede serlo por incompatibilidad con los hechos, con lo manifestado por las víctimas?, o iha ido aprendiendo que las mentiras le sirven aunque sean burdas? Nos interesaremos en los datos del programa de intervención con agresores sexuales recibido por V.S.R., pero primordialmente en la valoración de los responsables del mismo: ¿ha sido exitoso?, ¿en qué?

\section{Informe psicológico solicitado para la aplicación de medidas sustitutorias de la pena a menores, $\mathbf{2 6}$ de marzo de 2003}

Durante su permanencia en prisión ha participado en actividades específicas de tratamiento dirigidas hacia la tipología del delito cometido (2000 y 2001). 
- Evaluación del tipo delictivo: no se ha diagnosticado la aparición de rasgos patológicos incidentes en la capacidad volitiva o cognitiva del sujeto, en la comisión de los delitos. Rasgos característicos del perfil básico del agresor sexual: negación inicial de los hechos, mecanismos de defensa centrados en distorsiones cognitivas, baja capacidad para desarrollar emociones de identificación y empatía hacia la víctima, limitaciones en el área de competencia social.

- Continuidad del tratamiento y pronóstico de reincidencia: el sujeto enmarca su comportamiento de agresión sexual dentro de un perfil tipo que destaca su capacidad de discernir y elegir, situando la causalidad principal de la misma en la distorsión del sistema axiológico (cognitivo-emocional) destaca la necesidad de afrontar aspectos fundamentales como la prevención de recaídas y la intervención en fases sucesivas de adaptación al entorno social en que se ha de reinsertar.

Como vemos el psicólogo es muy cauto en relación al futuro de V.S.R. Hemos de subrayar su afirmación "situando la causalidad de su comportamiento en la distorsión del sistema axiológico (cognitivoemocional)", (lo que dice, piensa, razona; versus lo que le empuja a obrar y lo que siente o quizás ni sienta). Este psicólogo nos está dando una clave que nos señala la característica fundamental de los psicópatas.

\section{Informe de conducta. El educador del Centro Penitenciario Madrid-IV (Navalcarnero), 26 de marzo de 2003}

Durante su estancia en este Centro ha manifestado una conducta regimental adaptada, con asunción de la normativa institucional. Actitud respetuosa y educada. Asiste a la escuela a curso de graduado escolar, ayuda en el destino del office (reparto de comida).

Los datos referidos no los valoro como significativos en un suj eto que entendemos pudiera ser psi- cópata y abusador sexual. Es más, preocupa esa adaptación, esa "actitud respetuosa y educada".

\section{Informe del interno V.S.R., pertene- ciente al programa "Con una visión nueva". V. V. Psicóloga, Madrid, 10 de mayo de 2001}

Asistió de forma regular a las sesiones y su actitud fue favorable, mostró un positivo desarrollo en cuanto a la potencialización de sus habilidades sociales. La intervención busca modificar aquellos aspectos fundamentales en este tipo de delito: la conducta sexual, la competencia social y las distorsiones cognitivas (Marshall y Barbarie, 1989). La evolución de V.S.R. ha sido muy favorable en cuanto al logro de determinados obj etivos específicos al delito, como son:

- Superación de la negación y minimización. Es decir, reconocimiento del delito e internalización de la responsabilidad sobre el mismo.

- Modificación de creencias y actitudes distorsionadas.

- Expresión de sentimientos positivos y negativos (entrenamiento en intimidad y autorrevelación).

Se continúa trabaj ando con V.S.R. incidiendo en la empatía con la víctima y fantasías sexuales inapropiadas...

...confirmar la necesidad de la continuidad de la intervención... Considerar que la intervención actual es un primer paso para la adecuada reinserción social de V.S.R...

Nos quedamos con el último párrafo escrito por la colega "Ia intervención es un primer paso... sólo un primer paso".

No compartimos el "logro de determinados objetivos específicos al delito". Consideramos que no se da el reconocimiento del delito (como mucho acepta- 
ción por fuerza de las irrefutables pruebas), ni internalización de la responsabilidad sobre el mismo (véase que en el 2004 sigue manifestándome que el responsable real de las conductas es la droga).

Respecto a la expresión de sentimientos, mucho nos tememos que el entrenamiento le haya servido para armarse de palabras y explicaciones nada sentidas.

\section{Sentencia № EEE/99. Audiencia Provincial de Madrid. Sección Sexta. Sumario № X/98 del J uzgado de Instrucción № 38 de Madrid, 24 de julio de 1999}

\section{V.S.R. de 17 años, con domicilio en Madrid.}

Fundamentos de Derecho. Primero: Los hechos que se declaran probados, constituyen: a) tres delitos de robo con violencia e intimidación y uso de armas de los arts. 237, 242 no1 y 2 del C. Penal de 1995, norma penal que se considera más beneficiosa, y b) tres delitos de agresión sexual de los arts. 179 y 180 no5 del C. Penal de 1995, norma penal que al igual que el caso anterior se considera más beneficiosa para el culpable...

El procesado, con anterioridad al acto del juicio oral, negó los delitos que se le imputaban. En este acto del plenario, V.S.R. tan sólo respondió a las preguntas de su defensa, haciendo alusiones entrecortadas e inconexas a relaciones sexuales con las víctimas, pero sin penetrarlas y eyaculando fuera...

... La prueba acreditativa de la autoría se encuentra principalmente en los reconocimientos en rueda... Además prueba pericial biológica... las pruebas de esperma... el haberse encontrado en poder del procesado el reloj de P... el reconocimiento que las víctimas hicieron del cuchillo, de la cazadora azul, 0 de la mochila... o de las botas...

En la realización de dichos delitos concurre la circunstancia modificativa de la responsabilidad criminal y la atenuante de edad juvenil. Así mismo, la circunstancia agravante de aprovechamiento de las circunstancias del lugar y tiempo... Las aborda cerca de parques o descampados... a esas horas y en esos lugares que el delito queda más impune, que es en definitiva lo que se propone el culpable.

...Pero además, el procesado debe reparar esos daños morales que han sufrido las víctimas y que se hicieron patentes y evidentes en el acto del juicio, por lo que la suma de 6 millones de pesetas para cada una de ellas para reparar ese trauma moral es adecuado y equilibrado.

La Sentencia y de forma pedagógica nos recuerda que esta figura delictiva es el mayor atentado a la libertad individual, que su apreciación requiere que concurra cualquiera de las formas comisivas: acceso carnal, anal o bucal, y estas tres formas comisivas se han realizado contra las tres víctimas (ciertamente este dato es relevante, ¿qué visión tiene V.S.R. de la muj er y la sexualidad compartida?, ¿es un sádico?, ¿busca humillar?). Además el juzgador recuerda a las víctimas y responsabiliza al procesado: "debe reparar esos daños morales y que se hicieron patentes y evidentes en el acto del juicio". Bien está que se recuerde a las víctimas (en todo momento), que se les dé cabida en el procedimiento, que se las atienda (recuérdese que señalan sus miedos, su incapacitación para salir solas de noche, se les ha cercenado su libertad, pero al tiempo verbalizan que no han contado con apoyo psicológico).

¿Entenderían las víctimas o los ciudadanos la expresión de la sentencia "por lo que la suma de 6 millones de pesetas para cada una de ellas para reparar ese trauma moral es adecuado y equilibrado" ? Creo que no, rotundamente, No. 


\section{Acta del juicio oral, 23 de julio de 1999}

No se confiesa reo del delito que se le imputa.

Con carácter previo la Defensa renuncia a la prueba pericial psiquiátrica.

\section{Prueba testifical}

- Z, jura y dice al Mo Fiscal que el día 19 de julio del 98, salía del metro... y un chico se le acercó con una navaj a y fueron al parque... Que la obligó a que le masturbara, que hubo una penetración anal, que eyaculó cuando la penetró por detrás. Que le quitó el reloj, Lotus, dos mil pesetas... que la persona que reconoció en el J uzgado fue el que atentó contra ella,...Que con posterioridad a los hechos no ha recibido tratamiento psicológico.

- Y, jura y dice: que el día 22 de julio del 98, en la estación de metro (la misma que Z)... le abordó un individuo,...con una navaja......él dijo que le chupase el pene, que le chupó los pechos, que la penetró. Que la penetración fue vaginalmente, que eyaculó. Que la penetración oral fue anterior... le cogió el monedero y le quitó el bonobús, tres mil pesetas, ... Que la arrastró por todo el parque y sobre el muro él sabía donde había un hueco y la sacó por el hueco... Que llegaron al caj ero y le obligó a sacar 50.000 (cincuenta mil) pesetas, ella le dijo que le dejase el bonobús para irse a su casa y le dijo que ni hablar, que quedaba poco para que fueran las doce de la noche y que podría sacar otras 50.000 (cincuenta mil) pesetas.

...Que cuando fueron las doce fueron otra vez al mismo sitio, sacó las otras 50.000 (cincuenta mil) pesetas, y no la dejó marchar, y la llevó otra vez a una zona oscura del parque...

...Que fue al J uzgado, que hizo una rueda de reconocimiento y reconoció a una persona y se ratifica.

- X, promete y dice: que el 24 de julio del 98, al salir del metro de (próximo al de $Z$ y al de $Y$ ) ... oyó que alguien detrás de ella corría... esa persona se puso delante de ella, y le puso una navaja tipo estilete delante,... que la insultó, que la dijo hija de perra, sígueme... ella comenzó a gritar y entonces ya subieron unas persianas y él se debió asustar y se fue. Que no tenía duda del reconocimiento, ni la tiene...

- W, jura y dice: ... que apareció un chico, que la cogió por la cintura... que le amenazó con una navaj a... que al llegar al parque la tumbó en el suelo, registró su bolso, ... que le quitó el dinero, el reloj y una medalla con una cadena, también un paquete de caramelos... empezó a tocarla y le tuvo que masturbar y después realizar una felación, que como tenía ella el período le hizo una penetración anal... Que lo reconoció sin duda... Que por la noche no sale sola, tiene miedo, tiene pesadillas...

\section{Prueba pericial}

Peritos: J.J.; C.C. y M.M. Trabajadora social y médicos forenses, respectivamente.

J uran y dicen:

C. C. : que examinó al acusado, que hizo una exploración psiquiátrica... que el acusado le refería que no fumaba ni bebía, no consumía ningún tipo de droga ni pastillas. Que no encontró ninguna enfermedad de carácter psiquiátrico, que no tenía ningún rasgo patológico.

J . J .: manifiesta, que entrevistó al jefe del acusado, ... le dijo que el acusado tenía una actitud normal... Que la novia le dijo que la solía dejar en su casa sobre las once.

No se confiesa reo del delito que se le imputa (sin duda es un derecho Constitucional, pero en todo caso no asume culpabilidad, continúa afirmando que eyaculó fuera... se demostrará mentira. Miente, miente).

La Defensa renuncia a la prueba pericial psiquiátrica, lógico dado que no se ha detectado patología que pudiera argumentarse como eximente 0 
atenuante. Resulta difícilmente calificable su comportamiento, es un hielo que es capaz de robar tras haber violado y hacerlo con reiteración en el mismo cajero a la misma chica, sabedor del cambio de día a las 24 horas (¿cabe prueba más fehaciente de que obraba con total consciencia, y que hacía lo que quería hacer sabedor de que lo hacía?). A destacar esa característica de insultar a sus víctimas "hija de perra" ¿Es una forma de asustar, de amedrentar, o lo siente así, con ese odio, con ese desprecio?

Respecto a la prueba pericial, rescatar que le dijo a la médico forense que "no consumía ningún tipo de droga ni pastillas" (¿una nueva mentira o miedo a que en unas hipotéticas analíticas se reflejase que no era consumidor y que por ende la ingesta de droga era sólo una coartada?).

Relativo a las manifestaciones de la novia de V.S.R. a la Trabajadora Social "que la solía dejar en su casa sobre las once" (cabe preguntarse ¿era capaz de acompañarla, protegerla, "ponerla a buen recaudo" e irse a violar a otras mujeres? Sí, primero porque tiene una vivencia muy negativa de las intenciones aj enas y piensa que lo que él hace a otras mujeres, se lo pueden hacer a "la suya". Busca además satisfacer un impulso no sólo primario sino sórdido, desviado, pero desde luego hedonista y placentero para él (por eso reincidió).

\section{Informe psicológico del Equipo Técnico de Apoyo a Menores de los J uzgados de Plaza de Castilla, 29 de agosto de 1998}

La exploración consistió en: Entrevista individual con el informado. Exploración clínica. Antecedentes biográficos y familiares. Observación de conducta durante la entrevista. Vivencia subj etiva de hechos imputados. Síntomas psicopatológicos. Así mismo, entrevista con los padres del informado el 4 de septiembre de 1998. Contraste con los datos aportados, mediante 3 técnicas psicodiagnósticas: Cuestionario de Personalidad E.P.Q. -A de Eysenck.
Test de la persona de Machover. Test Guestáltico visomotor de Bender. Aprecian las psicólogas los graves problemas familiares.

Con muy buen criterio las psicólogas reflejan entrecomillada una frase de V.S.R. "alguien te mira y te tienes que pegar", frase repetida hasta la saciedad por los jóvenes beligerantes, antisociales, con mala percepción de las intenciones aj enas, muy significativo de quien busca pelea. Detectan perfectamente que están ante un manipulador: "busca la aprobación de las psicólogas, tratando de dar respuestas correctas".

Aprecian un bajo nivel de vocabulario "como expresión de un nivel cultural muy bajo". Dato relevante, pues seis años después ha adquirido una correcta fluidez verbal y un correcto bagaje de términos que utiliza con soltura, lo que confirma su buen potencial cognitivo, que se ha desarrollado en cuanto ha asistido a educación reglada.

Precisan con rotundidad: "sin signos de alteraciones psicopatológicas de orden psicótico". Nadie ha mencionado siquiera la posibilidad de una alteración mental, era y es un joven cuerdo, absolutamente responsable de sus actos.

Interesante también su dificultad para estar sólo (en el Centro Penitenciario de Alcalá Meco pide un compañero) "no puedo estar sólo, te vuelves loco ahí dentro". Pensar, hablar consigo mismo, conocerse le da pánico, tiene miedo de sí, de su introspección, es más fácil adaptarse o mejor dicho camuflarse en el exterior, que introducirse en ese aguj ero negro interior que sabe lleva dentro.

Quizás sea más fácil "pagar" por lo hecho con la privación de libertad y reingresar a la sociedad sin cargas morales, sin daños psíquicos, sin secuelas, sin planteamientos éticos que pudieran lastrar 0 hipotecar el futuro.

Impresionante la expresión "a mi novia no la saco por todo el ambiente que hay". Él (el macho) es el que puede sacarla o no y opta por la negativa porque piensa que hay otros muchos "machos" como él, auténticos cazadores furtivos. No olvidemos es- 
tas frases, definen a V.S.R. en su posicionamiento ante la muj er/ es.

Cabe preguntarse si no llegó a formularse mentalmente que toda aquella chica que no estaba a la hora que debía estar en su casa, coincidente con la que él llevaba a su novia a su hogar (para estar protegida), era merecedora de lo que le acontecía, o que al menos era corresponsable.

Clínicamente significativa resulta su incapacidad para entender la pregunta “¿Cómo se debe sentir una víctima de violación?" y le cuesta, porque le es novedosa, porque no se la ha formulado antes, si lo hubiera hecho, si tuviera capacidad para hacerse esa pregunta y ponerse de verdad en el lugar de la víctima, para empatizar, no habría cometido esas atrocidades que él seguro valora como achacables al azar (pudo ser esa u otra la víctima, mala suerte). Sí, así son los psicópatas, depredadores incapaces de sufrir con el sufrimiento del otro, ¡cuánto más de anticipar su sufrimiento!

A la pregunta de si cree que la víctima debe sentir miedo, manifiesta "por narices tienen que tener miedo", hay un punto de indignación en su respuesta, un ¡faltaría más que no fuera así!, porque él les demuestra su poder, su brutalidad, su insensibilidad, entiende que eso le hace distinto, hasta admirable.

La frase la concluye con un "a no ser que sea una fresca que le dé igual”. ¿Pero cómo interpreta la sexualidad, como un acto placentero genital, donde no influye el otro, ni la voluntad, ni la humillación, ni...?

La interiorización que tiene de la figura femenina es deplorable.

Las pruebas objetivas (tests psicológicos) nos muestran a una persona que necesita del contacto con los demás-pudiera ser superficial-, que puede ser insensible y muy impulsivo (quiere decirse que con los años, el paso por los centros penitenciarios y el centro de reforma ha aprendido a dominarse, a controlarse, a auto-limitarse).
La interpretación de las psicólogas del test de la figura humana, nos indica una inmadurez sexual e identificación con la figura materna ¿Estamos ante una relación real o percibida como Edípica, piénsese en el padre ausente y el hermano mayor toxicómano? En hechos así no cabe descartar ningún vestigio razonable. ¿Ha podido sufrir el gran incesto, con las funestas consecuencias que la experiencia profesional nos ha mostrado?

La última prueba demuestra que no hay indicadores que den como resultado la existencia de ningún trastorno orgánico como consecuencia del consumo de pastillas.

\section{Detención. Brigada Provincial de Policía Judicial 3aㅡ, Delincuencia Sexual y Malos Tratos, 2 de agosto de 1998}

... como consecuencia del servicio de vigilancia establecido en diferentes estaciones de Metro, donde en días anteriores se han producido distintos delitos Contra la Libertad Sexual y Robos con Intimidación, detectaron a las veintitrés horas del día 1-VII-98, la llegada a la estación de Metro... de un joven... y quedándose... en actitud de espera observando a las personas que salían de la misma.

... Dado que las características de este joven coincidían con las aportadas por al gunas de las víctimas y su comportamiento era de vigilancia, los funcionarios actuantes optaron por identificarse como Policías... que se procedió a su detención... encontrándole en el bolsillo del pantalón la navaja...

Diligencia: Han comparecido Z...Y... X... W... Se les ha mostrado un álbum criminológico de fotografías... de individuos... de... características físicas similares a las del detenido V.S.R.

Z reconoce sin ningún género de dudas...Y reconoce sin ningún género de dudas a V.S. R...X reconoce sin ningún género de dudas... ha reconocido sin ningún género de dudas, una cazadora y una navaja. 
Estamos ya en disposición de explorar a V.S.R.

Tras realizar cambio de fecha por su participación en un "Casting", el 18 de junio de 2.004, en el despacho del psicólogo del Centro de Reforma El Pinar... V.S.R. realiza el test de personalidad 16 P.F., inmediatamente después, a las $10 \mathrm{~h} .30 \mathrm{~min}$. se inicia la entrevista, a un lado de la mesa el psicólogo del centro El Pinar, al otro V.S.R. y J avier Urrá (psicólogo de la Fiscalía del Tribunal Superior de Justicia, Sección de Menores de Madrid). La entrevista dura un total de 3 horas 15 minutos ininterrumpidos.

La sesión exploratoria resulta intensísima y agotadora, discurre con total fluidez pero hay momentos de tensión (no de violencia), de lágrimas por parte de V.S.R., de hipotética sorpresa, de gestos, de palabras, de intentos de convicción... sin percibirse en V.S.R. pérdida de control físico 0 emocional...

Respecto al ambiente familiar inicia su comentario diciendo que era bueno, al referirle problemas explica "en casa había problemas, pero yo siempre he sido fuerte psicológicamente. Mi padre tenía problemas pero el problema era el alcohol, no él". En primer lugar y como siempre niega la realidad, lo evidente, luego lo reconoce y lo explica con un razonamiento verbal que parece lógico pero que analizado es pueril e insostenible.

En todo caso parece que su infancia fue complicada, vivió con sus tíos y luego con sus padres feriantes, las relaciones de los padres eran francamente malas, la droga y el barrio golpeaban su entorno.

Respecto a su historia personal explica "Al ser feriante perdía mucha asistencia al colegio, luego no me centraba, valía para los estudios, pero me pasaba el día haciendo gamberradas y por eso dejé el estudio" (fracaso escolar, magnífica autoimagen siempre hipertrofiada-. ¿Cuál ha sido su patrón de socialización?).

Relativo a los amigos de esa etapa explica "Yo me sentía seguro con mis amigos, me apoyaba en ellos" (¿padre grupo?). Acaba su fase escolar, prontísimo "a los 14 años trabajaba ya en la carnicería con horario de 8 a 20 horas" (comprobaremos más tarde que los horarios no coinciden pues nos indica que a las 6 horas estaba en MercaMadrid; en otro momento dice que estaba toda la noche divirtiéndose...). Explica que "ya no hacía gamberradas, los amigos eran sanos".

Iniciamos el abordaje al tema emocional-sexual de V.S.R. y nos comenta "desde los 14 años he tenido la misma novia y nos comprometimos, pero yo le he fallado. Era una chica fabulosa, yo iba con otras chicas, pero no se lo decía para no hacerla daño. Luego me arrepentía pero no sabía decir que no a las chicas, yo era pasivo cuando ellas me tonteaban" (volvemos a encontrarnos con que el problema viene o está fuera, las chicas le tonteaban y que él es incapaz de dominarse, pero además no se lo comenta a su novia por el bien de ella. Retuerce la realidad. Sus racionalizaciones chocan frontalmente con su forma de actuar).

Preguntado por su vida sexual (masturbaciones, fantasías sexuales, etc. ) contesta varias veces con "normal", derivando la conversación a otros ámbitos. Eso sí, niega la posibilidad de que le atraigan los varones (pero no se siente ofendido por la pregunta), tampoco parece reaccionar ante la insinuación de una posible equívoca relación con la madre, que niega de plano. Para llegar a este punto se le ha ido indicando que precisamos conocer su yo profundo, si existe alguna patología, alguna causa no descubierta que dé razón a sus conductas, que pudieran ser no sólo delictivas sino desviadas, que queremos junto a él conocerle, si es que se conoce, que a lo mejor descubrimos algo que nos sorprenda que dé explicación y respuesta a tantas dudas.

El caso es que V.S.R. continúa "mi novia creía que yo acabaría mal, o que me llevaría a alguien por delante o que acabarían conmigo", sigue el hilo argumental y explicita "yo antes tenía un gran descontrol, salvo que era muy trabajador" (¿qué había apreciado su novia?, nada indica que una desviación sexual, pero sí una forma de vida despreciativa de las normas, al límite del riesgo, 
violenta). Prosigue "en aquella época no reflexionaba, no me paraba a pensar. Salir por la noche era otro mundo, tenía dos (2) mundos, uno responsable con mis padres, con mi trabajo y con mi novia y otro por la noche una vez que dejaba en su casa a mi novia" (reincide en ese momento de ruptura que le significa el dejar a su novia "a buen recaudo" en su casa) (¿Es verdad que tenía dos mundos?, lo cierto es que la novia conocía sus andanzas).

Continúa, "yo siempre he tenido claro que mis padres estaban allí. Lo que me decían era por mi bien, pero no les hacía caso, es raro, pero es así, me pasaba también con la novia, una cosa eran las razones y otra mi conducta, quizás ése es mi problema" (creo que acaba de definirse, claramente, con rotundidad, esos son dos mundos ocultos, la palabra, las razones es uno atractivo, el otro son los impulsos, el hedonismo, el desprecio al otro).

Al tocar el tema de la sensibilidad dice "yo he llorado mucho y lloro todavía, me desahogo, expulso la rabia. Yo lloraba por mi familia y por lo que le hacía a mi novia" (va mostrando lo que cree esperamos de él, ¿realmente lloraba y llora?, no da en absoluto la impresión de que así sea). (Me pregunto ¿llorará a lo largo de la entrevista?).

Se define como "yo soy extrovertido, con ganas de vivir, soy social, buena persona, soy noble, con ganas de triunfar" (ciertamente es extrovertido y quiere vivir, es más, triunfar, lo hecho, hecho está y él necesita ser conocido y reconocido, cree merecerlo. Hoy por hoy se ha presentado a un "casting". Fijémonos que dice soy buena persona, ¿lo cree? Y noble, aquí nos encontramos con una disyuntiva del tipo: "siempre miento". Lo que hay que discriminar es si dice que es noble para seguir mintiendo ganando en fiabilidad, o es que de tanto mentir no reconoce la mentira ni a él como a un mentiroso empedernido. Dada su autodefinición le pregunto qué tiene de negativo o mejorable, contesta "yo no me veo nada negativo, soy eso sí perfeccionista, no sé si eso es negativo" (impresionante, si no fuera tragicómico, es incapaz de encontrarse un defecto).
Se recrea escuchándose "yo no sé si los problemas que he tenido me conllevó a hacer eso". "Creo que todos los problemas estaban en las drogas" (ha cerrado el círculo dialógico. Pobre niño feriante, con padre alcohólico afecto de S.I.D.A., trabaja con 14 años, no soporta la presión, cae en la droga y ésta le impide saber lo que hace, pero él es bueno y lucha por triunfar). Llegados a este punto creo que es el momento de sincerarme, de golpear su argumentación, su seguridad, su historia aprendida. Veamos como acepta el envite, intentemos captar su realidad emocional, el eco de sus sentimientos.

Le hablo con claridad meridiana, dura, coherente, con datos, mostrándole sus ingentes contradicciones, retomando datos significativos del expediente, recordándole lo expresado por las víctimas. Datos, detalles inatacables, abrumadores. Es un brutal análisis de realidad. Le hago saber que nadie nunca le ha podido creer, que ningún psiquiatra o psicólogo forense de España le creería, que ningún experto en drogas defendería su versión. Que miente y miente, que se refugia en frases hechas. Que en un juicio, en el próximo juicio nadie va a creer en esa patraña, que en el anterior nadie le creyó, que ni la defensa solicitó analíticas para apreciar el grado de adicción a drogas.

El momento es tenso, el silencio cortante se dilata, acaba diciendo "nunca me habían dicho eso". "Pienso que la gente me cree". Continúa manifestando que todo el problema venía ocasionado por la droga. Le digo que no, que la droga encubre algo, que quizás se drogaba para realizar las violaciones. Que tenemos que dirimir si tiene problemas sexuales o es un antisocial que roba el dinero y la intimidad de las mujeres.

Retomado el tema sexual expresa que "me masturbaba normalmente de niño". "Tuve relaciones sexuales a los 13 años con una chica utilizando el preservativo, fueron orales y vaginales, fue un juego y nos gustó a los dos". "Luego he mantenido relaciones estables completas con la novia, no anales" (destacar su precocidad y promiscuidad y que a las chicas violadas las penetró también analmente ¿tiene al guna significación?). Gira la conversación 
y dice "he pensado que los problemas de niño me pudieron llevar a hacer esas cosas".

$Y$ de pronto sin una pregunta que ej erza de efecto disparador dice: "Voy a contar una cosa que nunca he dicho, de pequeño un joven me obligó a masturbarlo". "No quisiera que eso salga de entre nosotros". "Creo que esto puede dar razón a lo hecho". Continúa "creo que lo que me pasó de pequeño me ha llevado a lo que hice. Esto no se lo he contado a nadie, a nadie...". Créanme si les digo que lo estaba esperando, una explicación acorde, necesaria, que llega en el momento justo.

Esta vez estoy convencido, lo sé, miente.

Ha comprobado que anteriormente no le he creído, que vengo de la Fiscalía de Menores, que fue él quien pidió verme quizás para que yo ratificase su beatitud, que pronto irá a juicio y su futuro de libertad o prisión está sin decidir. Y le dice/ nos dice, pero yo he sido el Defensor del Menor, que él de niño fue obligado a masturbar a un joven. En un momento pasa de ser verdugo a víctima. Un golpe de efecto, si no fuera porque no es creíble. Y no es creíble porque no lo ha dicho antes, años y años con psicólogos con educadores y me lo dice a mí, que es la segunda vez que me ve. Y no es creíble porque lo dice de una forma tan vaga que no cumple ninguno de los criterios para credibilidad del testimonio para niños presuntamente víctimas de abusos sexuales de Undeütsch (1989) y de Séller (1989). Es más, en cuanto se le pregunta dice que quien se lo hizo ya no vive allí. Además y continuada la entrevista desliza un "ya se sabe que los niños abusados y maltratados cometen cosas" (en otro momento comenta que ha leído libros psicológicos).

No, no es creíble ni como lo dice, ni lo que dice (y lo ratifica quien ha conocido a auténticas víctimas de abusos). Pero es que además ¿quién ha sostenido que un niño al que se le obliga a masturbar a otra persona, ha de violar reiteradamente a punta de estilete, robando y humillando? Lo que ocurre es que cuando realicé el análisis de realidad filtré que por sus hechos pareciera que odiaba en esas mujeres, al mundo, y que ese odio se debía a algo. Acababa de darme la respuesta. Y dice que no se lo contemos a nadie por lo que le podría suponer a su madre. ¿El qué?, ¿entender por qué su hijo cometió tales atrocidades? Una madre, que tiene un marido alcohólico, con S.I.D.A., que la ha violentado, con dos hijos en las cárceles, uno de ellos heroinómano, esa mujer ¿se va a impresionar porque su hij o siendo muy niño tuviera que masturbar a un joven?, no parece excesivamente lógico.

El firmante a partir de esta declaración de V.S.R. adopta una posición mucho más silenciosa, escasamente intervencionista, de reflexión interior. Deseo que piense que le creo, que me pongo a su lado, que comprendo que todo se explica. Desde ese instante V.S.R. se "crece", dilata sus expresiones, las va hilando como un argumento que encaja. Si lo pensamos tampoco cambia tanto, antes el problema era la droga, ahora un malvado que le obligó a masturbarle cuando era niño. El foco del problema es externo. Eso sí, ahora hasta el hipotético consumo de droga no le es achacable.

Se le pregunta por las víctimas y de forma mecánica pero sin contenido, sin un detalle vívido, sin un gesto de sensible humanidad dice "Yo he empatizado con ellas, nunca me liberaré de ese tema", "pienso en todo, en mí, en cómo lo han pasado, no sé explicarlo, no sé decirlo, pero pensando en el futuro, en mí, lo tengo muy en cuenta todo" (diagnósticamente significativo, comienza y termina "en mí" y cuando tiene que hablar de ellas no sabe, porque le es imposible, porque no tiene contenido, porque no se imagina qué han sentido, cómo lo vivencian, qué repercusiones ha tenido en sus familiares, en sus parejas). Sabe que les habrá afectado, pero porque todo el mundo lo dice, no tuvo sensibilidad cuando las violó y no se le detecta -ni un ápice ahora-, aunque quizás él quiera sentir, necesite sentir. Pero su corazón en este aspecto está adormecido, acorchado.

Respecto al mañana dice "veo el futuro bueno, soy trabajador. Mi padre está estable, mi hermano ha salido de la cárcel y está desenganchado. Crearé una cooperativa" (realmente la situación es delicada, pero él y como siempre no ve problemas). Estamos terminando la larga entrevista, le pregunto, ¿crees que me voy con alguna duda?, contesta 
"creo que con el dato que te he dado ya no te vas con ninguna duda". Es verdad me voy sin dudas, creo que miente, que inventa, que es un psicópata y lo escribo con pena, porque el psicópata no se beneficia de atenuantes ni eximentes y así debe ser, hace lo que hace porque lo quiere hacer, pero es terrible porque nos encontramos con un joven que desde cortísima edad demostró su insensibilidad hacia los otros ¿cuál es la razón?, no lo sé, desde luego en esa sórdida infancia se esconde entremezclada la respuesta.

Acabamos la entrevista con su última contestación "No creo que necesite ningún tipo de apoyo psicológico ulterior".

Concluyente.

Le cito para el próximo viernes 21 de junio en el Centro El Pinar a las 9 horas. Volveremos a encontrarnos los dos psicólogos (del Centro de Reforma y del Ministerio Fiscal) y V.S.R.

Y así es.

Le recabo sobre la entrevista del otro día y explica "me pareció bien, se aclaró más la cosa, que estaba un poquito liosa, no le di importancia porque yo ya tenía conocimiento del tema". "La reunión no me ha quitado tiempo porque tenía todo asumido". Sinceramente creo que nada le quita el sueño, salvo su porvenir, su futuro. Lo que es sorprendente -al menos para el firmante- es que no se dé cuenta de que su futuro es incierto en todos los sentidos.

Le pregunto sobre qué le sería más difícil hablar, si sobre el pederasta (así le llama) que le obligó a masturbarle o sobre las violaciones que ha cometido, contesta que igual, comenta que él nunca habla de violación, sino del error que cometió.

Cuando le verbalizo que no es coherente lo que dice, que creo que nunca se ha parado a pensar, comienza a ponerse nervioso, suda por la frente, "tamborilea" con la mano, dice "al entrar en prisión reflexioné". El tono de los entrevistadores es amable, pero por primera vez capto en V.S.R. su nerviosismo, algo no encaja y él se percata, se lo explico gráficamente, si A es el suceso de la masturbación y conllevó como consecuencia las violaciones $B$ y desde entonces no se ha intervenido sobre $A$, ¿cómo saber que cuando sea libre $C$ no reincidirá? Responde "en las sesiones de tratamiento como abusador sexual no decía lo que me había pasado, pero me sirvió para aprender habilidades sociales" (estoy de acuerdo, preocupado, pero de acuerdo).

Prosigue "yo estoy psicológicamente bien, lo tengo todo superado", "yo me he tratado a mí mismo" (no tiene recato en decirlo, es un narcisista sin parangón). Le comento lo antedicho, con un tono bajo, afectuoso pero claro y directo, le hablo de la sociedad que está ahí fuera, de las víctimas que fueron y de las que pudieran ser, de las dudas gravísimas que tengo, de que creo que miente muchísimo pero que lo hace para llenar de contenido lo que no sabe explicar porque no lo siente, que de verdad me da pena, que quizás yo esté equivocado pero que considero que requiere mucha ayuda psicológica profunda. Y que me importa él, pero mucho más las víctimas y las personas que están fuera, que el futuro es el suyo pero también el de los demás. Que quizás le convenga seguir privado de libertad para asistir a un tratamiento profundo catártico.

Se esfuerza en ser convincente, próximo (lo consigue) y dice "yo me siento bien y superado y quiero demostrarlo, lo estoy haciendo con las salidas, me estoy esforzando en el trabaj o, con mi novia, ayudo a mis padres. El hecho de por qué lo hice no cambia mi futuro" (¿de verdad que no es importante saber por qué lo hizo? o es simplemente que sabe que no hay una causa que lo justifique, que lo hizo porque lo quiso hacer y ya está, y en el fondo desprecia que estemos indagando tras lo simple, lo obvio).

Abordo como se siente al caminar por su barrio, pues sus violaciones las llevó a efecto próximo a su casa -pese a que disponía y se desplazaba en moto-, si tiene miedo a la situación de encontrar- 
se con alguna víctima o familiar/amigo de éstas, responde con un tono y actitud colérico, prepotente "Yo no le doy importancia a encontrarme con una víctima" "Yo voy por mi barrio con la cabeza alta". Su respuesta y forma de realizarla me hace pensar: no lo conocemos en la calle, en su entorno, menos con un estilete en el bolsillo o en la mano.

Concluyéndose la entrevista, le comento que ciertamente tiene derecho a ser feliz, pero también le planteo que quizás él no sea consciente pero posiblemente sea lo que se denomina un psicópata, que lo he pensado mucho, analizado y estudiado con atención y que sinceramente siento pena, porque he llegado a la convicción de que miente reiteradamente, que se inventa realidades porque tiene un terrible vacío, porque no siente, porque sabe que tiene que decir lo que dice pero no lo siente, porque le angustia a él mismo su realidad, su frialdad, su incapacidad. Porque no se atreve a decirse, a decir, a decirnos, que lo hizo porque lo quiso hacer y que no ha sufrido por ello, que no se lo ha planteado profundamente, esa es -según mi parecer- su tragedia y el riesgo para la sociedad. Quizás es una víctima de un entorno, de un fracaso educativo, pero ahora es un verdugo que no puede garantizar su no reincidencia.

Y por ello le hago ver que quizás le viniera bien seguir un tratamiento psicoterapeútico profundo y específico que de verdad aborde sus carencias, que le reestructure cognitiva y emocionalmente, mucho más allá de capacitarle con habilidades sociales. Le explico que quizás fuera bueno que ese tratamiento se llevase a efecto estando privado de libertad, para su tranquilidad y la de los ciudadanos que están al otro lado de las rejas. Contesta y lo hace dolido, preocupado "Volver a la cárcel me partiría, sería un paso atrás. Sería terrible para mí, para mi familia". "Si tuviera que seguir una terapia la podría hacer fuera, no en la cárcel".

Ahora sí se le ve angustiado, considerarse él privado de libertad más tiempo le agobia. ¡Qué distinto su posicionamiento y actitud en este momento, respecto al adoptado cuando hablaba de las víctimas!

\section{Pruebas objetivas}

Se le administra el 16 PF Fifth Edition, de Cattell R. B. ; Cattell A. K. S. y Cattell H. E. P. de 1993; se incluyen tres medidas de estilos de respuesta (deseabilidad social, infrecuencia y aquiescencia).

Nos muestra a una persona autosuficiente que sin embargo en su yo profundo es insegura y se preocupa (V.S.R. se muestra seguro y autosuficiente, pero no se conoce profundamente y es muy perfeccionista y ordenado).

Valoremos la P. C. L. (Escala de Psicopatía de Hare) y específicamente la actualización y versión de 1989.

Hare y colaboradores (1991) han identificado dos factores de correlación en el P. C. L. El factor I corresponde a la personalidad intrínseca peculiar de la psicopatía. En este Factor I, al firmante le da la puntuación máxima en psicopatía. Determinante.

Respecto al Factor II valora los rasgos conductuales característicos del estilo de vida crónicamente inestable. En este caso existe un sesgo importante y es que V.S.R. en los últimos años ha estado privado de libertad por lo que la valoración queda invalidada.

\section{Diagnóstico}

V.S.R. es un joven afecto de un gravísimo trastorno psicopático de la personalidad, con base antisocial en su infancia y juventud (Urrá, 2005).

Los gravísimos y reiterados hechos que cometió fueron fruto de su nula valoración de los sentimientos del otro y de su concepto negativo de la mujer.

Es un hedonista que busca su placer y cuyo principio de vida es "primero yo y luego yo".

Su patología hunde sus raíces en su infancia, en sus vivencias familiares muy negativas, en el sufrimiento de unas realidades que desestructuraron su maduración y evolución. 
Además nos encontramos ante un individuo que ya entonces y ahora es absolutamente narcisista, posee una autoestima patológicamente elevada y está convencido de que sus dotes de seducción le permiten mentir con reiteración enfermiza sin que el interlocutor lo detecte.

En todo caso tampoco le importa mucho lo que los demás piensen o sientan.

Se valora como "muy fuerte psicológicamente" y en ese sentido preocupa su perfeccionismo autoeducado en estos años de privación de libertad junto a las intensas sesiones de implementación de habilidades sociales que ha supuesto un aprendizaj e para dificultar el correcto diagnóstico.

No hemos podido apreciar un solo detalle de vinculación con las víctimas (otra cosa es que dice "he empatizado").

Ciertamente cree que ya "ha pagado" con la pérdida de su libertad lo hecho, pero no tiene ninguna acepción ética, moral, profundamente humana.

V.S.R. hoy se comporta de forma correcta y adaptada a las normas del centro, pero no es relevante, no asume ninguna culpabilidad, la deriva a la droga, otros hechos, etc.

Recordemos que tras violar oral, vaginal y analmente era capaz de robar a la víctima un paquete de caramelos o la tarjeta de un cajero de la que obtenía dinero antes de las 24 horas e inmediatamente después.

En las conclusiones de los autores especialistas vemos que los psicópatas manifiestan un alto egocentrismo-narcisismo (Millon, 1981), tienen un sentido de la autoevaluación grandilocuente. Mc. Cord (1982) ha demostrado una alta correlación entre padres agresivos y alcohólicos con la conducta psicopática de los hijos. Para obtener los fines anhelados, el psicópata se provee de un gran encanto superficial (Hare, 1980), algo que es favorecido por tener una personalidad extrovertida. Para estos sujetos la mentira y el engaño son parte integradora de su relación con los demás (Cleckley,
1976; Hare, 1980). Debemos recordar que el psicópata es un gran manipulador, que se sirve de cualquiera en su propio beneficio personal. Podemos decir de él que se trata de un consumado actor (Hare, 1980). Un rasgo importante a tener en cuenta es la ausencia de remordimientos o sentimientos de culpa (Hare, 1980).

El diagnóstico de V.S.R. se basa en datos empíricos, es el caso de su manifiesta distorsión cognitiva, con una actitud muy negativa hacia las mujeres (creencia que caracteriza a los violadores).

Las agresiones que cometió V.S.R. le engloban en el grupo del violador depredador, siente que está legitimado para violar, la víctima estaba en el sitio equivocado, en el momento equivocado. La agresión es un acto de depredación, no se preocupa por ocultar su identidad, a veces va provisto de un arma.

\section{Orientación}

V.S.R. precisa un tratamiento psicoterapeútico exhaustivo que acometa su pensar y sentir profundo, que le habilite para conocerse, y no mentir/ se, para captar al otro y sobre todo a la víctima, al tiempo de restaurar su visión de la sexualidad y apreciación de la figura de la mujer.

Alcanzar en este momento la libertad supondría un grave riesgo para el resto de los ciudadanos y un apoyo a los criterios de V.S.R. que se sostienen en la nada.

\section{Informe psicológico del interno V.S.R., Expediente de Ejecución xx/2003}

Solicitado por la fiscal de ejecución de medidas de la Fiscalía del Tribunal Superior de J usticia, sección de menores, 14 de agosto de 2004

El caso de V.S.R. es significativamente singular, por todo ello y pasado un tiempo razonable desde la Audiencia (1 mes) era preceptivo mantener un 
encuentro-entrevista con el interno que lo fue de 3 cárceles, para posteriormente pasar a Centro de Reforma de Menores (aplicación derecho Transitorio a la entrada en vigor de la Ley de Responsabilidad Penal del Menor 5/ 2000) y ulteriormente (hace exactamente 1 mes) volver a ingresar en el Centro Penitenciario de Navalcarnero.

Relativo al juicio dice "no tuve mucha defensa en el juicio". "No fue justo que no me dieran la libertad vigilada. Creo que era buena la terapia, pero se podía hacer fuera, como se demuestra con el aprovechamiento que hice al salir a trabajar". "Yo sí me expliqué bien". "Me fui preocupado por ver preocupados a mis padres".

"Yo aquí lo estoy pasando mal, por la pérdida de contacto con la familia, estaba demostrando ser sociable. He perdido el trabajo".

"Creo que no se está pensando en mí".

"Hay miedo a tomar una decisión -nadie se mojano se cree en la resocialización".

"Creo que el tratamiento psicológico debe ser continuado, no puede ser que los tratamientos se rompan, es el caso de la psicóloga con la que me entendía muy bien en El Pinar, pero luego la echaron y volver a empezar no es fácil, contar lo profundo a alguien y volver a empezar".

“En estos días -1 mes- estoy muy nervioso y no puedo pensar en lo que hice, ahora esto me está machacando". "A veces pienso: Pago el año y medio y luego ya demostraré".

"Pienso, no puede ser que por haber cumplido 23 años me hagan una regresión".

"Yo preciso el 3o grado, vengo de una situación distinta. Me puede faltar un tratamiento, pero puedo hacerlo en semi-abierto...".

“Yo de hacer un tratamiento psicológico en la cárcel quiero hacerlo individualmente".

Respecto a los hechos explica "Es verdad lo que usted me dijo, yo he mentido mucho porque creo que es una forma de defensa, yo entré con 17 años y tenía un miedo atroz". "Me ha dado miedo buscar la verdad y por eso lo achaqué a las drogas...".

“He descubierto 2 tipos de profesionales psicólogos: los que se mojan (la del Centro de Reforma y usted. ), y en la cárcel una psicóloga de C.U.P.I.V. (total 3 implicados de 9 o 10)". "Pocos psicólogos van a la persona". "Los tratamientos psicológicos en grupo sirven para aprender habilidades sociales, pero no son para profundizar en los problemas personales".

\section{Valoración}

Encontré a V.S.R. físicamente bien, sin embargo su actitud ha cambiado mucho, mostrándose casi indefenso y suplicante.

La decisión judicial de internarle en prisión le ha impactado profundamente. Desea ajustarse a la nueva situación, pero ésta le desborda.

Está bajo el efecto de un "shock".

Por ello y por primera vez se sincera profundamente con el firmante al que le reconoce que ha mentido y lo ha hecho reiteradamente durante años.

Ahora sí, explicita que no sabe el por qué de los gravísimos hechos que cometió y aún más, solicita terapia profunda, individual.

No podemos dejar de pensar que tan radical cambio pudiera esconder otra manipulación, cual es buscar salir del centro penitenciario puntualmente para actividades psicoterapeúticas.

En todo caso se le aprecia angustiado, perplejo, desvalido.

Es cierto que el cambio de situación ha sido brutal, que ha perdido algo fundamental, como es el trabajo y la relación con la familia y con su "novia". Lo vive como una regresión. 
Pero no es menos cierto que el impacto que ha recibido ha hecho mella en su yo hipertrofiado.

Encontré a V.S.R. -y entiéndaseme la expresiónmucho más humano, en tanto que sufre, que siente, que duda, que se interroga.

V.S.R. dice verdades en esta entrevista, no es la menor que un tratamiento como el suyo debe ser continuado por la misma persona, que no es factible, iniciar/ acabar/ reiniciar y abrirse a otras personas.

Y cierto es que hay profesionales que no se involucran, que no acometen la ardua labor de intentar conocer a la persona, de profundizar.

V.S.R. requiere tratamiento, lo solicita. Precisamos dárselo. Pero creo no equivocarme al decir que la privación de libertad en este momento le es positiva, tanto por lo antedicho (hoy se formula preguntas), como aprendizaj e de que realizar ciertos hechos supone un costo personal importante.

Y sin embargo esta visión positiva del momento presente de este facultativo, podría volverse en contra si la situación a partir de un tiempo (aproximadamente 2 meses) se cronifica sin alternativas esperanzadoras.

Ratificamos la propuesta que en su día se realizó: V.S.R. precisa más sanción y más tiempo para la reflexión y la psicoterapia, pero no privado mucho tiempo de total libertad, pues corremos el riesgo de que "se rompa" o se "adapte" interiorizando el criterio "pago con mi libertad y ya está".

Reiteramos que el caso de V.S.R. es particular por el proceso que ha vivido (cárceles-centro de reforma que concluyó en semi/ abierto/ libertad-regreso a prisión).

Ulteriormente y durante mucho tiempo mantuve reunión con el psicólogo y el jurista que entienden del caso. Conocen profundamente el expediente y específicamente el informe realizado por el firmante. Expliqué mi diagnóstico y propuesta.

Existe una total coincidencia en la valoración y prospectiva por lo que ambos profesionales verbalizaron que mantendrán el planteamiento reflejado en este informe.

- 9 de marzo de 2005.

Se nos informa de que han conseguido mediante un convenio, que V.S.R. asista a una unidad de psicoterapia clínica adscrita a la Universidad "W" de Madrid.

· 18 de abril de 2005.

Entrevista telefónica con V.S.R. (continúa preso).

Me informa que ha salido en el día de ayer, a mantener la primera sesión psicoterapéutica, con las dos psicólogas (a las que ya conocía, pues le habían visitado en la cárcel), que le ha resultado interesante y que su disposición es muy positiva.

Le explico que por fin estamos realizando lo que tanto deseábamos por entender necesario, que continuaré efectuando el seguimiento de su evolución y que confío en entrevistarme con él fuera de la prisión, alguno de los días en que le den permiso.

El caso V.S.R. es paradigmático, había pasado por casi una decena de psicólogos antes de ser explorado en el último momento por mí, la libertad estaba al alcance de la mano, V.S.R. se había portado bien en prisión y en el centro de reforma, su conclusión era obvia, estaba sano, lo que realizó, pasó hace años, no es sino un mal recuerdo, un mal sueño que nada tiene que ver con él, ni con su futuro, porque entiende que su proceso ha sido correcto, que no se han producido recaídas, que de lo contrario al go le habrían dicho los profesionales de los centros penitenciarios y de reforma.

Pero yo, J avier Urrá (y lo digo en primera persona, para responsabilizarme al $100 \%$ ), he comprobado con asombro y angustia que en prisión y en los centros de reforma no se trabaj a -de manera genérica- con los agresores sexuales de una forma profunda y sistemática. Y ello debido al altísimo número de reclusos, a los cambios de institución de quien está privado de libertad, a rotaciones de los profesionales, a negativas reiteradas de los agre- 
sores, a una inconsciente postura de no horadar en una herida que conlleva desequilibrios y riesgos conductuales, con quien se va a convivir durante mucho tiempo.

Se trabaja y mucho en habilidades sociales, en capacitación para acceder al mundo laboral... pero poco, muy poco en las "razones" que llevaron al o a los hechos, a buscar junto al ya paciente la etiología de sus conductas y de los riesgos de reincidencia

Pasan los días, las semanas, los meses, los años en un mundo artificial, estructurado, absolutamente supervisado, sin riesgo, sin tentaciones. Su escasa capacidad de autocontrol se debilita.

Creemos que con el paso del tiempo, con el miedo a una sanción que ya conocen, el riesgo de reincidencia casi desaparece y no es así. Salen a la calle y se encuentran desubicados, sin apoyo, en un entorno que no les facilita cubrir sus necesidades emocionales y sexuales como la sociedad entiende aceptable.

\section{Referencias}

Cattell, R. B., Cattell, A. K. S. \& Cattell, H. E. P. (1993) Questionário 16PF (5a ed.) Rio de J aneiro: CEPA.

Clekley, H. (1976) The mask of sanity. San Luis: Mosby.

Hare, R. D. (1980) La psicopatía: teoría e investigación. Barcelona: Herder.
Hare, R. D.; Hart, S. D. y Hapur, T. J. (1991) Psychopathy and the DSM-IV criteria for antisocial personality disorder. J ournal of Abnormal Psychology, 100.

Marshall, W. L. y Barbaree, H. (1989): Sexual violence, en K. Howells \& C. Hollins (eds.) Clinical approaches to aggression and violence. Nueva York: Wiley.

Mc Cord, J. (1982) The pychopath and milien therapy. Nueva York: Academic Press.

Millon, T. (1981) Disorders of personality DSM-III: Axis II. Nueva York: John Wiley \& Sons.

Steller, M. y Koehnken, G. (1989) Análisis de declaraciones basado en criterios. En D. C. Raskin (ed.) Métodos psicológicos en la investigación criminal. Nueva York: Springer Publishing Co.

Undeutsch, U. (1989) The development of statement reality análisis. En J. Yuille (ed.), Credibility assesment: a unified theoretical and research perspective. Dordrech: Dluwer Academic Publishers.

Urrá, J. (Comp.) (2002) Tratado de psicología forense. Madrid: Siglo XXI.

Urrá, J . (2003) Agresor sexual. Madrid: EOS.

Urrá, J. (2005) Adolescentes en conflicto (4ạ ed.) Madrid: Pirámide. 